\title{
Eriômetro de Young
}

\author{
(Young's Eriometer)
}

\author{
Renê Robert ${ }^{1}$ e Sérgio L.M. Berleze ${ }^{2}$ \\ ${ }^{I}$ Universidade Federal do Paraná, Departamento de Eletricidade, Curitiba, PR, Brasil. \\ ${ }^{2}$ Universidade Federal do Paraná, Departamento de Física, Curitiba PR, Brasil.
}

Recebido em 13/10/03; Aceito em 4/2/04

\begin{abstract}
Sugere-se um experimento clássico de difração de Fraunhofer, de baixo custo e fácil execução experimental, que fornece como resultado a determinação do diâmetro de micro-partículas de forma geométrica e dimensões semelhantes entre si.
\end{abstract}

Palavras-chave: difração, eriômetro, glóbulos sangüíneos.

A classical experiment of Fraunhofer's diffraction cheap and of easy execution is suggested. It supply also the determination of the diameter of microscopic particles, provided they are similar in form and dimensions.

Keywords: diffraction, eriometer, blood globules.

\section{Introdução}

Quando se estudam os fenômenos luminosos, em geral inicia-se pela óptica geométrica, a qual é baseada em proposições basilares denominadas de princípios fundamentais, tais como a propagação retilínea da luz e o conceito de raio luminoso. Existem situações em que esta abordagem não se aplica, por exemplo: a difração da luz, a propagação da luz em meios não homogêneos e em campos gravitacionais segundo a relatividade geral. Dentre estas, a que nos interessa neste trabalho é o fenômeno de difração. Quando um feixe de luz incide nos bordos de um obstáculo opaco, a propagação da luz não é mais retilínea e neste caso franjas claras são observadas na região de sombra [1]. Este fenômeno é chamado de difração e indica que a luz tem um comportamento ondulatório. Estes fenômenos foram relatados pela primeira vez por F. H. Grimaldi (1618-1663) e R. Hooke (1635-1703) e sua explicação fundamenta-se na teoria ondulatória da luz, a qual foi delineada por Christian Huyghens (1629-1695) e desenvolvida por A. Fresnel (1788-1827). Na difração trabalha-se basicamente com três elementos: uma fonte luminosa, um obstáculo e um anteparo de observação. Os fenômenos de difração são classificados em dois tipos: Fresnel e Fraunhofer. Quando as distâncias da fonte ao obstáculo e do obstáculo ao anteparo são finitas, a difração recebe a nome de difração de Fresnel. Quando estas distâncias são infinitas a difração recebe a denominação de difração de Fraunhofer (1787-1826). Os detalhes matemáticos da difração de Fresnel e de Fraunhofer não serão tratados aqui.

Existem muitas aplicações técnicas do fenômeno de difração, sendo algumas delas de fácil execução experimental. Um exemplo é o Eriômetro de T. Young (17731827) $[2,3]$. Neste dispositivo a difração obtida é do tipo

Enviar correspondência para Renê Robert. Universidade Federal do Paraná, Departamento de Eletricidade, C.P. 19047, 81531-990, Curitiba, PR, Brasil. E-mail: rene@lactec.org.br
Fraunhofer e com ele é possível determinar o diâmetro de partículas microscópicas tais como glóbulos sanguíneos e pó de licopódio.

\section{Prolegômenos teóricos}

A Fig. 1 mostra um esquema para obtenção da difração de Fraunhofer. As lentes $\mathrm{L}_{1}$ e $\mathrm{L}_{2}$ são utilizadas para satisfazer a condição de Fraunhofer, que considera a fonte e o observador no infinito. No obstáculo $\mathrm{S}_{1}$ existe um orifício circular de raio $R$. A linha tracejada central é o eixo de simetria do sistema óptico.

O formalismo usado para o cálculo do padrão de difração produzido por um elemento difrator (abertura ou obstáculo), na aproximação escalar, é a fórmula de Fresnel-Kirchhoff $[3,4,5]$ :

$U_{p}=-\frac{i k U_{0} e^{-i \omega t}}{4 \pi} \int_{A} \frac{e^{i k\left(r+r^{\prime}\right)}}{r r^{\prime}}\left[\cos (\hat{n}, \vec{r})-\cos \left(\hat{n}, \vec{r}^{\prime}\right)\right] d A$

onde, conforme a Fig. 2, $U_{p}$ é a perturbação óptica no ponto $\mathrm{P}$ devido a fonte $\mathrm{S}, \mathrm{k}=2 \pi / \lambda$ é o módulo do vetor de onda e

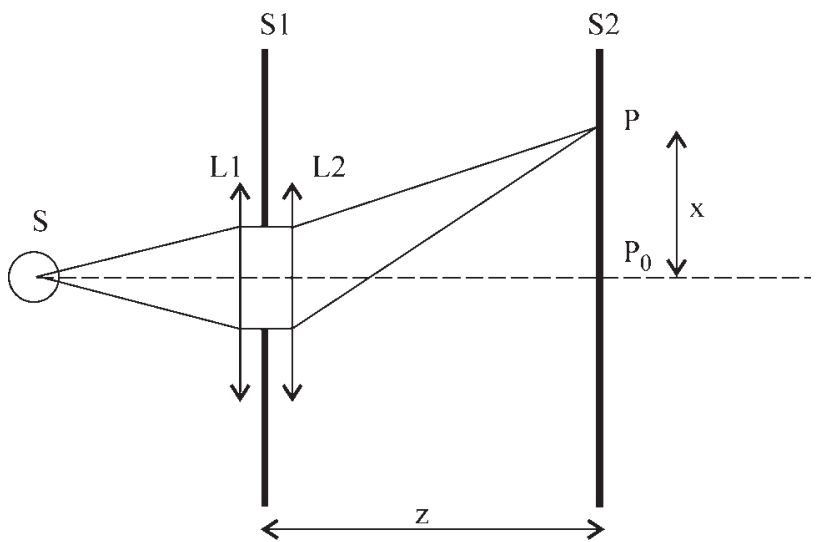

Figura 1 - Montagem experimental para obtenção da difração de Fraunhofer. As lentes são necessárias para que os feixes sejam colimados, o que é fundamental neste tipo de difração. 
$U_{0}$ é a perturbação óptica no elemento de área $d A$ devido a fonte S. Esta fórmula é válida quando $r$ e $r$ ' forem muito maiores que o comprimento de onda $\lambda$.

A iluminação no ponto P é dada por $I \propto\left|U_{p}\right|^{2}$. Considerando a geometria da Fig. 1, onde o ponto de observação P está a uma distância $x$ do ponto $\mathrm{P}_{0}$ e a lente $\mathrm{L}_{2}$ está a uma distância $z$ do anteparo de observação $\mathrm{S}_{2}$, e supondo que o elemento difrator seja uma abertura circular de raio $R$, a fórmula de Fresnel-Kirchhoff fornece para a iluminação no ponto $\mathrm{P}$ a expressão seguinte $[3,4,5,6]$ :

$$
I=I_{0}\left[\frac{2 J_{1}(\rho)}{\rho}\right]
$$

onde foi usada a definição $\rho=(2 \pi / \lambda)(\mathrm{R} x / z)$, na qual $\lambda$ é o comprimento de onda da radiação. Na Eq. (2) $J_{l}(\rho)$ é a função de Bessel de primeira espécie e ordem 1,

$$
J_{1}(\rho)=\frac{\rho}{2}-\frac{\rho^{3}}{2^{3} 1 ! 2 !}+\frac{\rho^{5}}{2^{5} 2 ! 3 !}-\frac{\rho^{7}}{2^{7} 3 ! 4 !}+\ldots
$$

A Fig. 3 mostra o aspecto qualitativo da figura de difração de Fraunhofer e a Fig. 4 ilustra o comportamento de $\mathrm{I}(\rho) / \mathrm{I}_{0}$. Observe-se a rapidez na queda da intensidade dos anéis.

A Tabela 1 resume os valores dos raios $(x)$ para os quais a Eq. (2) apresenta máximos e mínimos, e que correspondem aos anéis claros e escuros, respectivamente. Estes valores estão expressos em unidades de $\rho=z \lambda / 2 R$. Na coluna da intensidade relativa foi considerada a intensidade de cada anel claro em relação ao máximo central.

Segundo o teorema de Babinet, usando obstáculos em lugar de aberturas, geometricamente iguais, os padrões de difração observados são iguais.

O mesmo modelo pode ser aplicado para um grande número $N$ de elementos difratores (abertura ou fendas) iguais. Pode-se mostrar [3] neste caso que a iluminação no ponto de observação é expressa como o produto de dois fatores. O primeiro depende da iluminação devida a um elemento difrator e o segundo depende do arranjo dos elementos difratores. No caso particular em que o arranjo é aleatório a iluminação total no ponto de observação é igual a $N$ vezes a iluminação de um único elemento difrator. Este resultado é válido qualquer que seja a forma geométrica das partículas difratoras. As deduções feitas nesta seção enfatizam a forma circular para o orifício ou obstáculo, com a

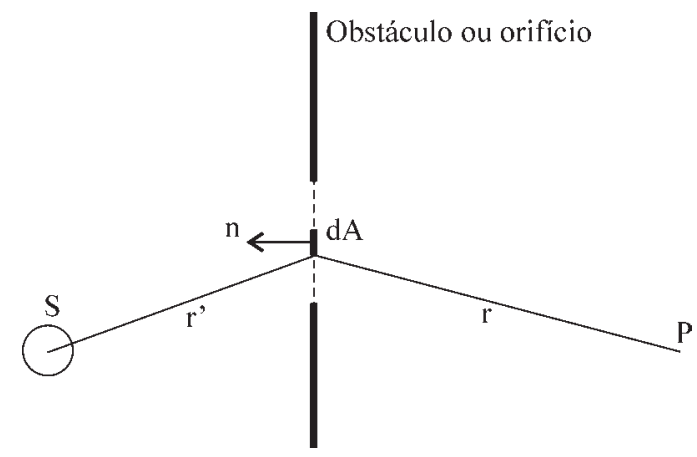

Figura 2 - Esquema para utilização da fórmula de Fresnel-Kirchhoff. A abertura no anteparo é o elemento difrator.

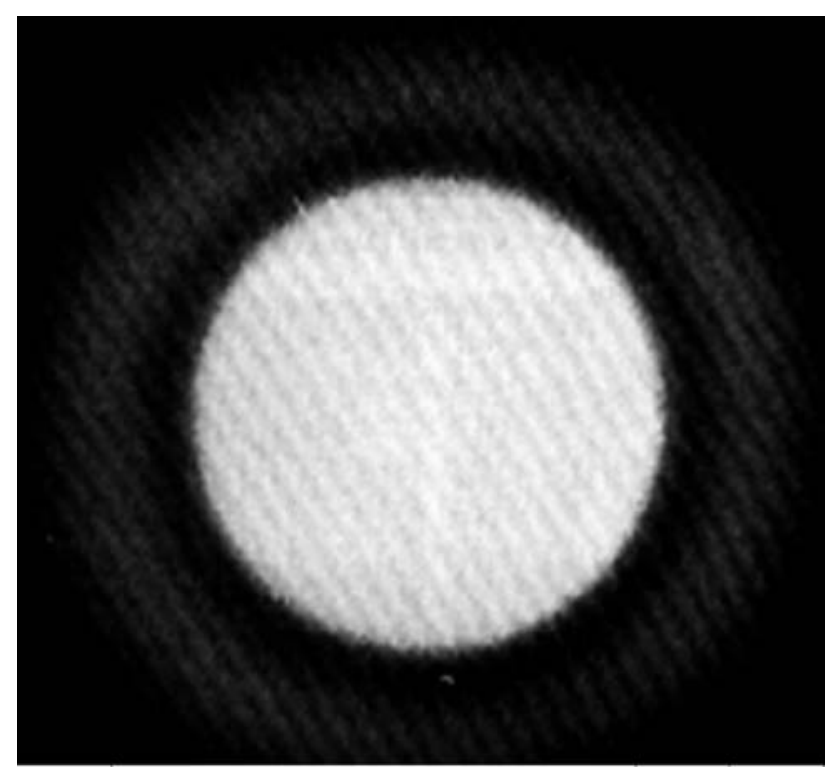

Figura 3 - Difração de Fraunhofer de partículas microscópicas. O padrão de difração tem um bom contraste quando se usa pó de licopódio ou glóbulos sanguineos com uma distribuição uniforme sobre uma lâmina de vidro.

Tabela 1 - Raios dos anéis claros e escuros numa figura de difração devido a uma abertura ou obstáculo circular.

\begin{tabular}{lccc}
\hline Anel número & Raio anel escuro & Raio anel claro & $\begin{array}{c}\text { Iluminação } \\
\text { relativa }\end{array}$ \\
\hline 1 & 1,22 & 1,64 & 0,0174 \\
2 & 2,23 & 2,69 & 0,0041 \\
3 & 3,24 & 3,72 & 0,0016 \\
4 & 4,24 & 4,72 & 0,0008 \\
5 & 5,24 & 5,72 & 0,0004 \\
\hline
\end{tabular}

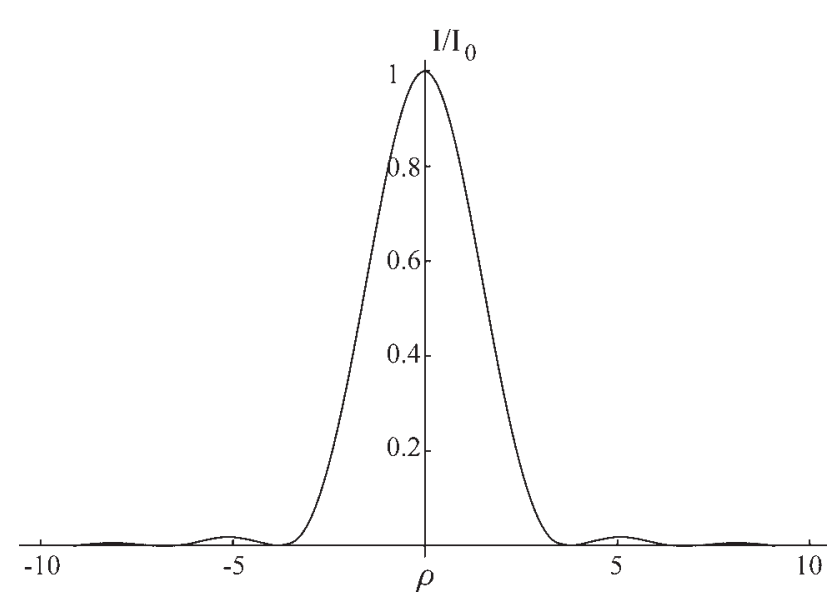

Figura 4 - Intensidade dos anéis de difração conforme a Eq. (2).

conseqüente formação de anéis, devido ao interesse em empregar pó de licopódio ou amostras de sangue no experimento. Caso as partículas tivessem outra forma geométrica, a figura de difração seria diferente; em alguns casos é possível prever teoricamente qual seria esta figura, por exemplo, para partículas difratoras retangulares ou alongadas na forma de fibra. 


\section{Experimento}

Para montar o Eriômetro de Young esquematizado na Fig. 5a é necessária uma chapa metálica AB de aproximadamente $0,5 \mathrm{~mm}$ de espessura. Nesta chapa faz-se $12 \mathrm{ou}$ mais furos, cada um com $1 \mathrm{~mm}$ de diâmetro, igualmente espaçados sobre uma circunferência de raio $r=75 \mathrm{~mm}$. No centro da circunferência faz-se um furo de $3 \mathrm{~mm}$ de diâmetro. A Fig. 5b ilustra os detalhes da furação. Na parte posterior da chapa é colocada uma fonte de luz S. Esta fonte pode ser uma lâmpada de vapor de sódio comum, quase monocromática, com comprimento de onda $\lambda=589 \mathrm{~nm}$. Uma outra possibilidade é utilizar uma lâmpada de filamento, incandescente ou halógena, com filtro verde F (papel celofane, $\lambda=560 \mathrm{~nm}$ ). Sobre uma lâmina de vidro $C D$, similar às usadas em microscopia, é disperso de maneira uniforme pó de licopódio ou uma amostra de sangue. O material disperso na lâmina deve ter partículas microscópicas e com forma e tamanho uniformes para que o efeito seja bem pronunciado. A lâmina de vidro CD é então colocada em frente ao olho do observador E. Observando através da lâmina de vidro, em direção à fonte, é possível ver anéis claros e escuros similares a aqueles mostrados na Fig. 3. Ajusta-se a distância $z$ entre a placa CD e a chapa metálica

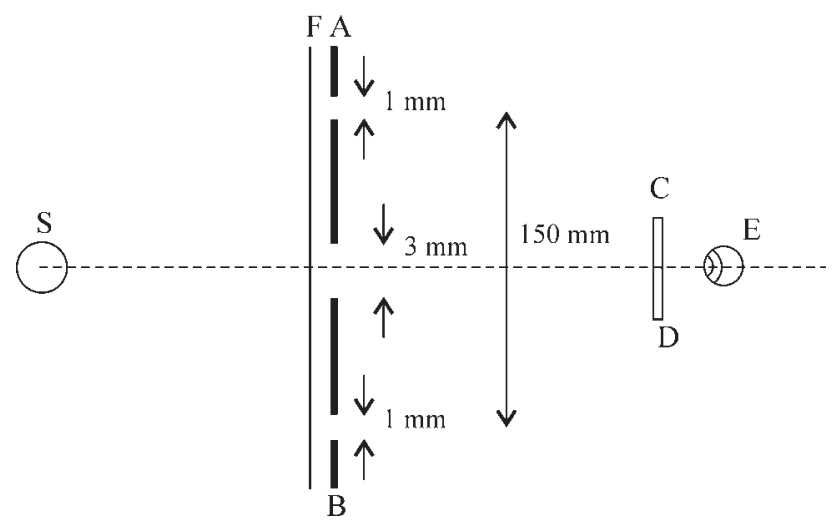

Figura 5a - Montagem experimental do Eriômetro de Young, onde AB é a chapa metálica, $\mathrm{F}$ é o filtro, $\mathrm{S}$ é a fonte luminosa e $\mathrm{CD}$ é a lâmina de vidro com os elementos difratores.

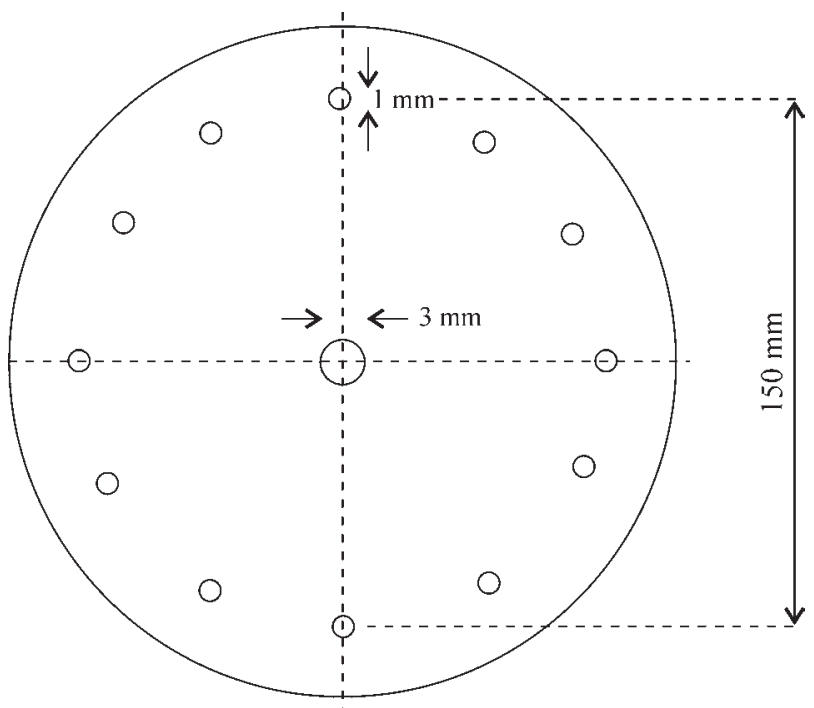

Figura 5b - Vista de frente da chapa $\mathrm{AB}$ mostrando os detalhes da furação. de modo a fazer coincidir a imagem de um dos anéis claros (ou escuros) com a imagem dos orifícios iluminados na chapa metálica. É necessário realizar o experimento em ambiente escuro. O diagrama de raios desenhado na Fig. 6 justifica porquê o observador vê estas imagens superpostas. Se for medida a distância $z$ da chapa ao observador é possível calcular o diâmetro das partículas microscópicas depositadas na lâmina de vidro. Fazendo, por exemplo, o primeiro anel claro de difração coincidir com os furos na chapa metálica e usando a Tabela 1, o diâmetro $a$ das partículas microscópicas será dado por: $\mathrm{a}=1,64 \lambda z / r$. Este experimento serve também para estabelecer uma comparação entre partículas com mesma forma mas diâmetros diferentes $a_{1}$ e $a_{2}$, através da expressão $a_{1} / a_{2}=z_{1} / z_{2}$.

A explicação para a obtenção desta figura de difração está em que um arranjo irregular de $N$ obstáculos similares entre si produz o mesmo padrão de difração que um obstáculo isolado, porém, com intensidade $N$ vezes maior [3].

Embora este experimento seja realizado em laboratório, fenômeno similar pode ser observado na natureza. Sob determinadas condições meteorológicas, a Lua pode ser envolvida por halos, devido à difração da luz em milhares de cristais de gelo formados nas camadas da alta atmosfera, embora nem sempre estes halos sejam devidos a este efeito.

Quando se usa uma amostra de sangue, o principal componente responsável pela formação dos anéis de difração são as hemácias, as quais têm a forma de disco. Assim, com esta experiência é possível fazer uma estimativa do seu diâmetro. Para este tipo de amostra a visibilidade das franjas é reduzida devido à variação do tamanho das hemácias, e pela presença de outras partículas que compõem o sangue com formas e dimensões variadas, entretanto, mesmo com esta limitação é possível realizar o experimento. Um cuidado importante está em espalhar corretamente a amostra de sangue sobre a placa de vidro, para que se forme uma monocamada. Deve ser usada a mesma técnica comumente empregada em laboratórios de análises clínicas.

Um modo ainda mais simples de obter figuras de difração consiste em usar um "laser pointer" (660-680 nm). Iluminando com o laser a lâmina de vidro contendo as partículas microscópicas, e observando sobre um anteparo a figura de difração podem-se medir os parâmetros geométricos necessários para o cálculo do diâmetro destas partículas. Quando medimos o diâmetro das hemácias por este método obtém-se um valor médio de $8,5 \pm 0.3 \mu \mathrm{m}$, sendo o valor determinado com auxílio de um microscópio aproxi-

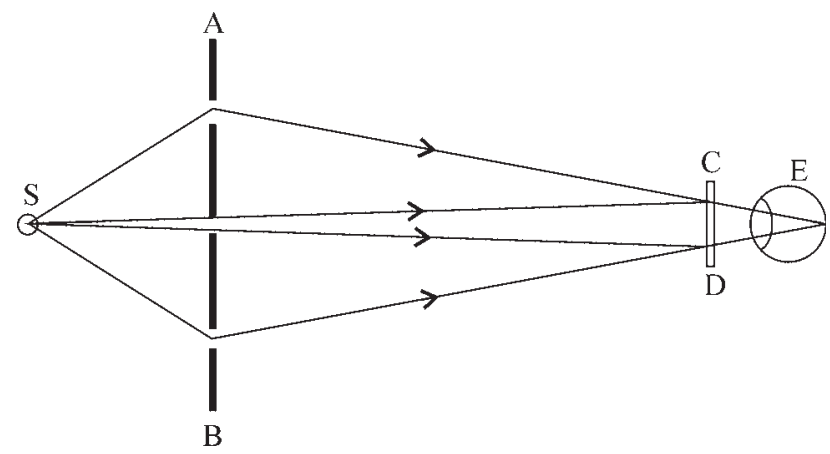

Figura 6 - Diagrama de raios mostrando a superposição das imagens dos furos da chapa $\mathrm{AB}$ e dos anéis de difração. 


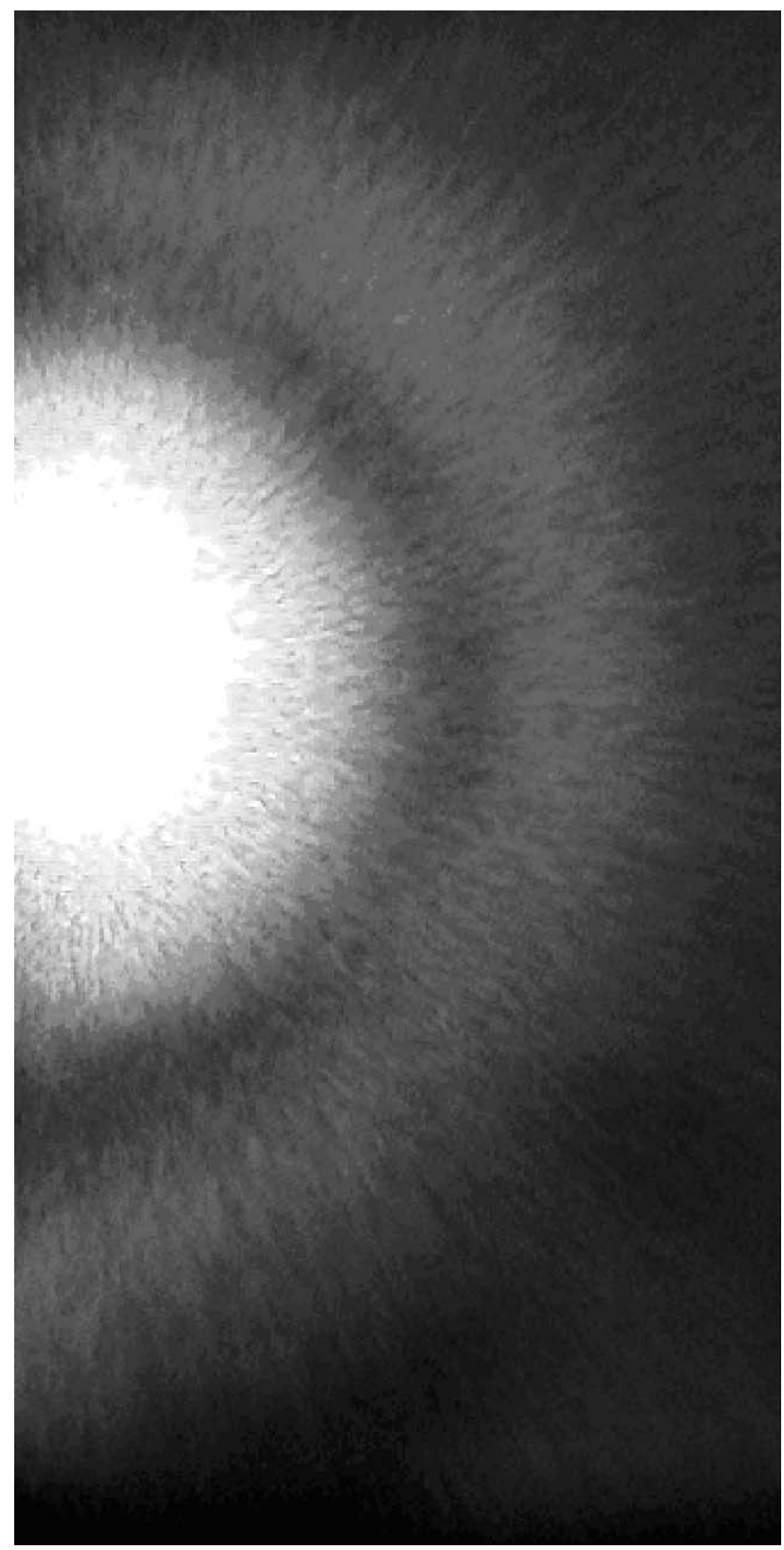

Figura 7 - Fotografia da figura de difração observada neste experimento.

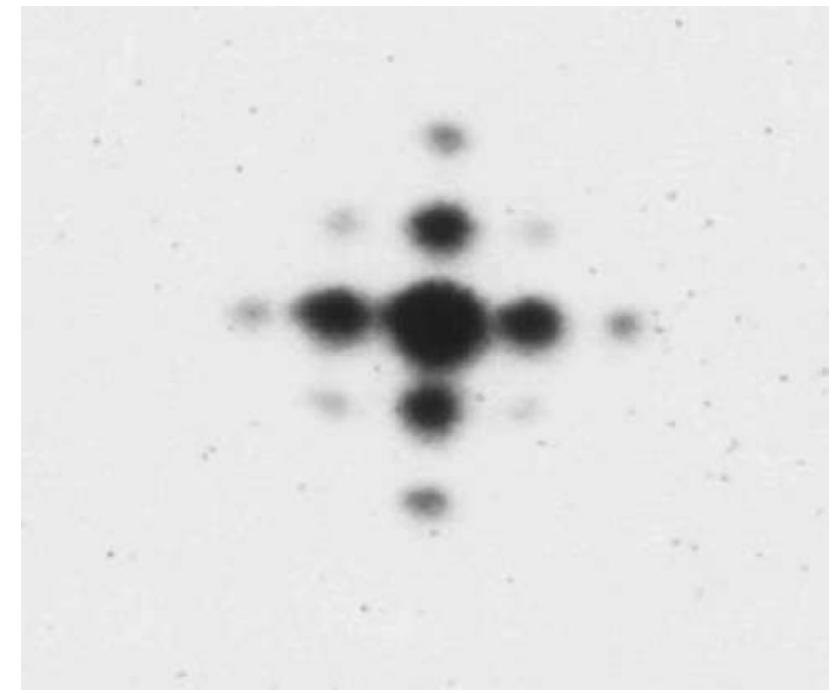

Figura 8 - Fotografia da figura de difração de um tecido usando como fonte luminosa um "laser pointer". madamente 9,0 $\mu \mathrm{m}$. Não recomendamos usar o laser no caso de observação visual direta pois este apresenta grande intensidade e pode ser danosa para a visão humana.

A montagem da Fig. 5a utilizando-se lâmpada de vapor ou de filamento tem a vantagem de permitir que se olhe diretamente para a fonte. $\mathrm{O}$ olho humano tem sensibilidade superior à dos filmes fotográficos usuais, principalmente quando adaptado à obscuridade. Para comprimentos de onda de $525 \mathrm{~nm}$ o limiar de sensibilidade visual é da ordem de 200 fótons [7], variando para mais ou para menos dependendo do observador. Se os olhos forem mantidos em baixo nível de luz durante certo tempo eles podem ficar mais sensíveis e uma determinada luz parecerá mais brilhante. As células de recepção, cones e bastonetes, adaptam-se em tempos diferentes, minutos e horas respectivamente [8]. Este fato permite o uso de qualquer tipo de fonte luminosa de baixa potência.

A fotografia mostrada na Fig. 7 foi obtida com este experimento ao se utilizar uma amostra de sangue. Como fonte de luz foi empregada uma lâmpada de vapor de sódio e a câmera foi colocada na posição onde ficaria o olho do observador. A qualidade da imagem registrada não é tão boa quanto a observada diretamente devido à razão exposta anteriormente.

A fotografia mostrada na Fig. 8 foi obtida usando como elemento difrator um tecido e como fonte de luz o "laser pointer".

\section{Conclusão}

O Eriômetro de Young é um experimento simples, de baixo custo e pode ser realizado em qualquer estabelecimento de ensino. Deve incitar a curiosidade do leitor em entender mais a fundo o fenômeno de difração da luz, um assunto importante não só no campo de óptica clássica como em experimentos de física moderna tais como difração de elétrons. Além do diâmetro de micropartículas, este dispositivo permite medir a espessura de fibras têxteis através da medida do diâmetro dos padrões de difração obtidos experimentalmente [9].

\section{Referências}

[1] H.M. Nussenzveig, Curso de Física Básica (Editora Edgard Blücher Ltda, S.P., 1998), v. 4, p.83.

[2] R.W. Wood, Physical Optics (The Macmillan Co., N.Y., 1934), p. 270.

[3] R.W. Ditchburn, Light (Academic Press, London, 1976), p. 151.

[4] K. Lizuka, Engineering Optics, (Springer-Verlag, 1984), p. 94.

[5] J.A. Brandão Faria, Óptica, Fundamentos e Aplicações (Editorial Presença, Lisboa, 1998), p. 128.

[6] R.S. Longhurst, Geometrical and Physical Optics (Longman, 1973), p. 245.

[7] S. Vavilo, Micro Structure de la Lumière (Editions en Langues Étrangères, Moscou, 1950), p. 12-13.

[8] R.L. Gregory, Olho e Cérebro, Psicologia da Visão (Zahar Editores, Rio de Janeiro, 1977), p. 78.

[9] W.J. Onions e B. Ellinghan, Measurements of Fibre Diameter Variation by Optical Diffraction, Br. J. Appl Phys. 10, 328 (1959). 